\title{
Production and shelf life determination of fruit/vegetable juices using watermelon, cucumber, pineapple and carrot
}

\author{
*Okwori, E., Onu, R., O. Adamu, M., Chindo, H., Dikko, H., Odunze, I.I, Baidu, A.L., Natala, C \\ and Eze, $P$. \\ National Agricultural Research Extension and Liaison Services (NAERLS), Ahmadu Bello University (A.B.U), Zaria, \\ Nigeria \\ ${ }^{*}$ Corresponding Author's Email: estherokwori777@yahoo.com.Phone: 07068798168
}

\begin{abstract}
Pineapple, water melon, cucumber and carrot are tropical fruits which tend to have short shelf - lives due to the climatic conditions of Nigeria. Processing them into juice and smoothies will reduce the amount of post harvest loss and create availability of natural fruit juice and smoothies in the market or at home for intake. Varieties of juice and smoothies were made from pineapple, watermelon, cucumber and carrot without adding any form of preservatives. Each fruit was blanched in a water bath for 5-10 minutes at (75-80) and thereafter blended with laboratory blender. These fruits were processed into juice and smoothies respectively, adding distilled water (1:1) and subsequently, sugar. The juice and smoothies were preserved under different temperature conditions, half were refrigerated and the other half left in a shelf at room temperature for three weeks. The products under experiment were subjected to sensory analysis before and after preservation based on taste, colour, flavour and texture at the end of three weeks (21 days). For the sensory evaluation, there were differences in all the quality attributes (colour, flavour, taste, and overall acceptability) after week 3. Carrot juice were more preferred (excellent) to carrot smoothies, (very good) in all the variables. Cucumber smoothies were preferred more to cucumber juice in taste, while cucumber juice was preferred in texture. Water melon juice and smoothies were most preferred in colour, flavour, taste and texture more. Also Pineapple with water melon juice was more preferred to Pineapple juice (very high acceptability).The two most accepted juice products were carrot juice and water melon/pineapple Juice. Shelf life of the product: The juice packaged in plastic and glass bottles and stored at room temperature loses both colour and taste after 21 days (3weeks) and starts to ferment. Refrigerated Juices and smoothies can be kept conveniently for more than 5weeks without changes in colour, flavour, taste and texture.
\end{abstract}

Keywords: Fruit juice, Shelf-life, Processing, and Sensory evaluation.

\section{INTRODUCTION}

Fruits are parts of flowering plant derived from the fertilization of specific tissues such as one or more ovaries (Mauseth et al., 2003). Fruits are highly perishable, non-staple foods which make up about 39\% of the food intake (fresh state or processed form) of people living in developing countries of Africa (Bates et al, 2001). Based on fruits antioxidant capacities, they are used as indicators for healthy nourishment as well as protection factors of the human body against oxidative destruction (Costescu et al, 2006). Fruits have been shown to contain high amount of minerals, moisture, low ash and crude fibre (Wall, 2006) and are sources of sugar, vitamin A, C and B groups, low protein and lipid (Ogbonna et al,2013). Fruit juices are liquid, nonalcoholic products with certain degree of clarity and viscosity obtained through pressing or breaking up of fruits with or without sugar or carbon dioxide addition (Costescu et al, 2006). Fruits and its juices constitute one of the most important foods for man. Their regular consumption maintains health and makes up for the losses in the human diet. Costescu et al, recommended the consumption of juices with pulp from foods and medicinal points of view. Fruits being a seasonal crop by nature have prompted many scientists to embark on 
researches on how to process fruit juices and preserve them for usage during off-season. Nutritional, chemical composition and the effect of storage on various fruits (oranges, pineapple, apples) and their juices have been reported by (Nararudeen 2010., Auta et al.,2011, Muhammad et al., 2013) reported on the shelf life of orange juice. Storage conditions on vitamin $\mathrm{C}$ and $\mathrm{pH}$ value of cashew apple juice was studied by (Emenike and Ebere, 2015).

Processing activities are of critical importance to expansion and diversification within the fruit and vegetable area and also in household as they increase market opportunities for fresh fruits and vegetables allows household varieties and add value while reducing postharvest losses. Again, processing improves the feasibility, productivity and effectiveness of fruit and vegetable production by increasing farm incomes, and creating rural employment and earning nationally (FAO, 2009).

Little processing eqiupment, packaging and natural preservation methods are all that is needed in the preservation of fruits and vegetables for households and rural dwellers to reduce post harvest loss and also meet the demand of "fresh-like" fruits drink of high quality which are nutritious, flavorful and stable for families and communities. These processing will focus on value addition with comparatively little product transformation while increasing product diversity (Ogbonna et al, 2013).

Economic growth and changes in dietary patterns have made both the production and consumption of fruit and vegetables increasingly important. The fruit and vegetable area has an important role in household nutrition, income enhancement, poverty alleviation, food security, and sustainable agriculture, especially in a developing country like Nigeria (Auta et al, 2011). Some studies estimate that about $30-40 \%$ of fruit and vegetables are lost, abandoned or underutilized after leaving the farm (Vasavada, 2003). A large number of these fruits and vegetables are however known for their therapeutic/medicinal and nutritive value. Household / consumers are becoming increasingly aware of the health and nutritional value of the food they consume, and there is an increasing tendency to reduce the consumption of chemically treated foods/ fruits / vegetables. An indigenous fruit like water melon, carrot, cucumber and pineapple plays a very vital role in fulfilling the nutritional / nutrient needs of individuals (Nazarudeen, 2010).

Watermelon (Citrullus lanatus) is a popular staple fruit in the world which is consumed equently as a dessert, fruit salad and used in garnishing drinks. It is a natural source of antioxidants (Alim-un-Nisa et al., 2012). Water melon is an unusual fruit source of the arotenoid lycopene and a rich source of phenolic antioxidants. It contains cucurbitacin E, a triterpene anti-inflammatory phytonutrient and unusual amounts of the amino acid citrulline (Dimitrovski et al., 2010). Water melon is an excellent source of immune-supportive vitamin $\mathrm{C}$. It is also a very good source of vitamin A (Sivudu et al., 2014). In addition, water melon is a good source of potassium and magnesium. The nutritional profile of water melon is full array of nutrients, including carbohydrates, sugar, soluble and insoluble fiber, sodium, vitamins, minerals, fatty acids, amino acids etc (Adedeji and Oluwalana, 2013).

Pineapple (Ananas comosus) is an economically important plant in the Bromelanceae family which encompasses about 50 general and 2000 species mostly epiphytic [Femandes, et al 2008]. The worldwide total pineapple production is between $16-19$ million tons (FAO, 2009). Pineapple and its juice demand continue to rise mainly due to increasing awareness of its health benefits (Nwachukwu, 2014). Its juice have an proximate composition of $81.2-86.2 \%$ moisture, $13-19 \%$ total solid of which sucrose, glucose and fructose are the main compositions, $0.4 \%$ fibre and a rich source of vitamin C (Dull, 2000). Pineapple also contains polyphenolic compounds and possesses antioxidant activity. Its pulp is juicy and fleshy with the stem serving as a supporting fibrous core. It is an excellent source of antioxidant, vitamin $\mathrm{C}$ which is required for healthy development. Pineapple juice is largely consumed around the world, mostly as canning industry by-products and in the blend composition to obtain new flavours in beverage and other products (De-Carvaiho et al 2007)

Carrots (Daucus carota) is a root vegetable with carotenoids, flavonoids, polyacetylenes, vitamins, and minerals, all of which possess numerous nutritional and health benefits. Carrots are good for eyes, carotenoids, polyphenols and vitamins present in carrot act as antioxidants, anticarcinogens, and immunoenhancers. Carrots can be as small as two inches or as long as three feet, ranging in diameter from one-half of an inch to over two inches. Carrot roots have a crunchy texture and a sweet and minty aromatic taste; carrots are associated with the colour orange (Harris et al,1999).

Cucumber (Cucumis sativa $L$ ) is one of the monoecious annual crops in the Cucurbitaceae family that has been cultivated by man for over 3, 000 years (Adetula and Denton, 2003; Okonmah, 2011). Cucumbers are 95 percent water." This makes cucumbers a great way to stay hydrated. Cucumbers contain several antioxidants, including vitamin $\mathrm{C}$, betacarotene and manganese, as well as flavonoids, triterpenes and lignans that have anti-inflammatory properties. The anti-inflammatory compounds in cucumbers help remove waste from the body and also reduce skin irritation. Vitamin $\mathrm{C}$ is well known for its immune system benefits, and beta-carotene has been shown to be beneficial for vision, according to researches.

With respect to economic importance, it ranks fourth after tomatoes, cabbage and onion in Asia (Eifediyi and Remison, 2011), and second after tomato in Western 
Europe (Phu, 1997) though its place has not been ranked in tropical Africa because of limited use. Soft and succulent, the vegetable crop is cherished by man and eaten in salads or sliced into stew in tropical regions. Its juice is often recommended as source of silicon to improve the health and complexion of the skin (Duke, 1997). Cucumber is a very good source of vitamins $A, C$, $\mathrm{K}$, B 6, potassium, pantothenic acid, magnesium, phosphorus, copper and manganese (Vimala et al., 1999).

Mixed fruit juice blends together can be produced from various fruits such as pineapple and vegetables such as carrot and cucumber and others in order to combine all the basic nutrients present in these different fruits. This usually gives a better quality juice nutritionally and organoleptically. Studies showed that the practice of mixing different exotic fruits and vegetables positively impact on the flavour and taste of the fruit/vegetables and its products [Baniigo et al 2015]. Moreover, one could think of a new product development through the blends of different fruits/vegetables in the form of a natural health drinks which may also serve as an appetizer. Evaluation of soy/carrot drinks flavored with beetroot was studied by Banigo et al., 2015 with the aim of developing new product or improving the existing one in the market. Therefore, to produce fruit juice/mixed from the blends of pineapple/ carrot/cucumber, determine shelf or storage and sensory properties of fruits in order to reduce post harvest lost are the objectives of this study.

\section{MATERIALS AND METHODS}

\section{MATERIALS}

Fully matured, ripe and fresh pineapple fruits, carrots and cucumber were procured from Samaru market, Zaria, Kaduna State, Nigeria. They were transported to Food technology and Rural Home Economics laboratory, NAERLS/ Ahmadu Bello University Zaria for subsequent study.

\section{METHODS}

\section{Preparation of carrot fruit juice}

Quality traits like uniformity in size, colour, shape and abrasion-free were considered in choosing the carrot, Pineapple and cucumber. The selected ones were sorted and washed thoroughly under running water after which they were washed with $5 \%$ hypochlorite solution to get rid of the surface microbes and contaminations. The Carrot (vegetable) were immediately rinsed severally with distilled water. The pericarp was removed and skin scraped with the aid of stainless knife and the fleshes cut into small pieces and separated into different bowl. The flesh blended with the aid of Sumeet Food Processor (Model A), then homogenized in a blender and filtered with the use of readymade double muslin cloth. They were packaged immediately and stored in airtight screw cap sterilized glass bottles then refrigerated at $5^{\circ} \mathrm{C}$ another half left at room temperature prior to evaluation.

\section{Preparation of pineapple fruit juice}

The fruits were selected and were washed with 5\% hypochlorite solution and rinsed thoroughly with distilled water. They were peeled with sterile stainless knife, cut into small pieces of about $3-4 \mathrm{~mm}$ thick and the juice extraction using a juice extractor (Iloytron, 23438, UK). The extracted pineapple juice was filtered by passing through a sterile muslin cloth folded into 2 layers, into a clean transparent bowl. The juice was bottled in an airtight screw cap sterilized glass bottles and refrigerated at $5^{\circ} \mathrm{C}$ prior to analysis and another half left at room temperature $\left(27^{\circ} \mathrm{C}\right)$

\section{Preparation of cucumber vegetable Juice}

The Cucumber (Vegetables) was immediately rinsed severally with distilled water. The pericarp and skin was removed with the aid of stainless knife and the fleshes were separated into different bowl. The flesh blended with the aid of Sumeet Food Processor (Model A), then homogenized in a blender and filtered with the use of readymade double muslin cloth. They were packaged immediately and stored in airtight screw cap sterilized glass bottles then refrigerated at $5^{\circ} \mathrm{C}$ another half left at room temperature prior to evaluation.

\section{Preparation of carrots /pineapple juice blends}

The carrot juice was blended with pineapple juice in a proportion of 30:70. The blends were homogenised, bottled and pasteurized at $80^{\circ} \mathrm{C}$ for $10 \mathrm{~min}$, cooled to room temperature $\left(27^{\circ} \mathrm{C}\right)$ and finally stored in a refrigerator at $5^{\circ} \mathrm{C}$ until analysed and another half left at room temperature for shelf life.

\section{Preparation of water melon Juice / water melon smoothes}

Water melon was washed severally with distilled water and the fleshes were separated into different bowl. The flesh blended with the aid of Sumeet Food Processor (Model A), then homogenized in a blender and the juice was filtered with the use of readymade double muslin cloth while the Smoothes was maintained in its original blended form. They were packaged immediately and 
Okwori et al. 037

Table 1. Results of Sensory Evaluation

\begin{tabular}{|c|c|c|c|c|c|c|c|c|}
\hline & Taste & & Colour & & Texture & & flavour & \\
\hline & Frequency & Percent & Frequency & Percent & Frequency & Percent & Frequency & Percent \\
\hline A1 & 2 & 28.6 & 2 & 28.6 & 1 & 14.3 & 2 & 28.6 \\
\hline \multirow[t]{2}{*}{ A2 } & Excellent & & & & & & & \\
\hline & 4 & 57.1 & 3 & 42.9 & 5 & 71.4 & 4. & 57.1 \\
\hline B1 & 2 & 28.6 & 1 & 14.3 & 1 & 14.3 & 1 & 14.3 \\
\hline B2 & 1 & & & & & Excellent & & \\
\hline & & 14.3 & 1 & 14.3 & 2 & 28.6 & 1 & 14.3 \\
\hline \multirow[t]{3}{*}{ B3 } & Moderately & & & & & & & \\
\hline & good & & & & & & & \\
\hline & 2 & 28.6 & 2 & 28.6 & 2 & 28.6 & 1 & 14.3 \\
\hline \multirow[t]{2}{*}{$\mathrm{C} 1$} & Excellent & & & & & & & \\
\hline & 6 & 75.0 & 4 & 50.0 & 3 & 37.5 & 3 & 37.5 \\
\hline $\mathrm{C} 2$ & 3 & 37.5 & 2 & 25.0 & 3 & 37.5 & 2 & 25.0 \\
\hline \multirow[t]{2}{*}{$\mathrm{C} 3$} & 1 & 12.5 & 1 & 12.5 & 3 & 37.5 & 1 & 12 \\
\hline & 2 & 25.0 & 1 & 12.5 & 1 & 12.5 & 1 & 12.5 \\
\hline \multirow[t]{2}{*}{ D1 } & Excellent & & & & & & & \\
\hline & 5 & 71.4 & 3 & 42.9 & 2 & 28.6 & 4 & 57.1 \\
\hline D2 & 4 & 57.1 & 2 & 28.6 & 2 & 28.6 & 2 & 28.6 \\
\hline
\end{tabular}

\section{Samples prepared}

$\mathrm{A}_{1}=$ Smoothes carrot, $\mathrm{A}_{2}=$ Carrot juice, $\mathrm{B}_{1}=$ Cucumber smoothes

$\mathrm{B}_{2}=$ cucumber juice, $\mathrm{B}_{3}=$ Non sweetener cucumber juice

$\mathrm{C}_{1}=$ Water melon juice, $\mathrm{C}_{2}=$ Water melon smoothes, $\mathrm{C}_{3}=$ Water melon smoothes control

$\mathrm{C}_{4}=\quad$ Water melon juice Control, $\mathrm{D}_{1}=$ Pineapple smoothes, $\mathrm{D}_{2}=$ Pineapple/water melon juice

stored in airtight screw cap sterilized glass bottles then refrigerated at $5^{\circ} \mathrm{C}$ another half left at room temperature prior to evaluation.

\section{Sensory evaluation}

The sensory analysis was carried out using ten member panelists consisting of staff of National Agricultural Extension Research liaisons services and Food Technology and Rural Home Economics Department, Ahmadu Bello University, Samaru Zaria. The sensory qualities evaluated were: Colour, Flavour, Taste and Overall acceptability. Portable water was provided to rinse the mouth before and between evaluations. The orange/pineapple juice blends together were served with clean gasses to individual panelist. Sensory attribute was considered on the basis of the following scale, very excellent, Excellent, good, very good, moderately good, Preferred, more preferred and most preferred.

\section{Statistical analysis}

Data were analyzed using Statistical Package for Social Science (SPSS) version 20.0 software 2012 and results were expressed in percentages.

\section{RESULTS AND DISCUSSION}

From the four fruits, Carrot, Pineapple, water melon and cucumber, were made four different types of juice, four smoothes and water and cucumber controls which was 
prepared along with the outer cover. Each fruit was made into two products (Juice and Smoothes) in its natural form From the sensory evaluation scores, $A_{2}$ was more preferred to $A_{1}$ in all the parameters, taste, texture, flavour and colour with $57.1 \%, 42.9 \%, 71.4 \%$ and $57.1 \%$ respectively while $A_{1}$ recorded 28.6, 28.6, 14.3 and 28.6 percentage, making $A_{2}$ more preferred and acceptable to $A_{1}$.

$B_{1}$ was more preferred to $B_{2}$ in taste $(28.6 \%)$ while both $B_{2}$ and $B_{3}$ were preferred in texture $(28.6 \%)$. The result shows both products were acceptable in all the indices.

$\mathrm{C}_{1}$ were more preferred over $\mathrm{C}_{2}$ in taste $75.0 \%$, colour $50.0 \%$ texture $37.5 \%$ and flavour $37.5 \%$ making it the most preferred in all the $\mathrm{C}$ product categories, followed $\mathrm{C}_{2}$ and $\mathrm{C}_{3}$ was the least accepted over all the juice in taste and colour.

$\mathrm{D}_{1}$ were more preferred in taste $71.4 \%$, colour $42.9 \%$ and flavour $57.1 \%$ over $\mathrm{D}_{2}$ with $57.1 \%$ in taste and $28.66 \%$ on in all others which includes colour, texture an d flavour. Results showed $\mathrm{A}_{2} 57.1 \%, 42.9 \%, 71.4 \%, 57.1 \%$ and $\mathrm{C}_{1}$ $75.0 \%, 50.0 \%, 37.5 \%, 37.5 \%$ in all the parameters as been the most acceptable product. (The two highest accepted juice products from the entire product were).

\section{Shelf life}

The products and all equipments used were properly handled, the fruits were washed clean and all the equipment used was all sterilized to avoid any form of contamination. The juice and smoothes were packaged in a plastic and glass bottles in their natural form and each form of the product made were selected into two equal half and stored in a shelf at room temperature and half were kept in the refrigerator for a period of four weeks. After panel tasted and obersavation, it was discovered that after three weeks (21days) the taste and colour of product stored at room temperature started to change and fermentation begin to take place. Products refrigerated were able to keep for more than one month (4 weeks) without any change. All this were stored in their natural form (without preservatives).

\section{CONCLUSION}

The different fruit/ vegetable juices / smoothies blends were successfully produced, shelved and undergo sensory physical evaluation. It was observed that almost all the sensory attributes of the fruits/vegetable juice and smoothies blends were excellent. This is to say that natural fruit / vegetables juices are better in terms of sensory parameter. All the fruit/Vegetable juices and smoothes was able to keep very well for at least three (3) weeks considering all the parameters assessed.The juice / vegetable sample that showed the least acceptability in all the sensory attributes such as colour, flavour, taste and overall acceptability was cucumber juice/smoothies (B1, B2 and B3).

\section{REFERENCES}

Auta R, James SA, Auta T, Sofa EM (2011). Nutritive value and photochemical composition of processed Solanum incanum (bitter garden egg). Science World Journal, 6(3), 5-6.

AOAC (2012). Official Methods of Analysis of the Association of Official Analytical Chemists, 20th ed.

Bates RP, Morris JR, Crandall PG (2001). Principles Practices of Smalland Medium- Scale Fruit Juice Processing. Available at: http://wwfao.org/docrep/005y251ey251e00htm.Accessed 17.09.2012.

Banigo EB, Kiin-Kabari DB, Owuno F (2015). Physicochemical and sensory evaluation of soy/carrot drinks flavoured with beetroot. African Journal of Food Science and Technology, 6(5), 136-140.

Costescu C, Parvu D, Rivis A (2006). The determination of some physico-chemical characteristics for orange, grapefruit and tomato juices. Journal of Agro Alimentary Processes and Technologies, 12(2), 429-432.

De-Carvalho JM, De-Castro IM, Da-Silva CAB (2008). A study of retention of sugars in the process of clarification of pineapple juice (Ananas cosmosus, L. Maeeil) by micro- and ultra-filtration. J. Food Engineering, 87(4), 447-454.

Dull GG (2000). The Pineapple. In: Hulme A.C ed. The Biochemistry of Fruits and Their Products, Academic Press, New York, 303-314.

De-Carvalho J.M, Maia G.A and De-Figueredo R.W (2007) Development of a blended non-alcoholic beverage composed of coconut water and cashew apple juice containing caffeine. J. Food Quality, 30, 664-681.

Emelike NJT, Ebere CO (2015a). Effect of packaging materials, storage conditions on the vitamin $\mathrm{C}$ and $\mathrm{pH}$ value of cashew-apple (Anacardium occidentale L.) juice. J. Food and Nutrition Sciences, 3(4), 160-165.

Emelike NJT, Ebere CO (2015b). Effect of packaging materials, storage time and temperature on the colour and sensory characteristics of cashew (Anacardium occidentale L.) apple juice. J. Food and Nutri. Res., 3(7), 410-414.s

Fernandes Jr. FAN, Linhares FE, Rodrigues S (2008). Ultrasound as pre-treatment for drying of pineapple. Ultrasonic Sonochemistry, 15(6), 1049-1054.

FAO (2009). Production Year Book. Food and Agriculture Organisation, Rome.

Mauseth PD, Sinisterra JV, Tsai SW, Alecantra AR (2003). Carica papaya lipase $(\mathrm{Cpl})$ : An emerging and versatile biocatalyst. Biotechnological Advantages, 24(5), 493-499.

Muhammad S, Saghir AS, Saima M (2013). Role of sodium benzoate as a chemical preservative in extending the shelf life of orange juice. Global Advanced Research J. Food Science and Technology, 2(1), 007-018.

Nazarudeen A (2010). Functional foods in the consumer interest? Food Science and Technology Today, 15-35.

Nwachukwu E, Ezejiaku FC (2014). Microbial and physicochemical characteristics of locally produced pineapple juice treated with garlic and ginger. IntL. J. Current Microbiology and Applied Sciences, 3(6), 895-901.

Nwachukwu E, Onovo OM, Ezema CF (2007). Effect of lime juice on the bacterial quality of zobo drinks locally produced in Nigeria. Res. J. Microbiol., 2, 787-790.

Ndife J, Awogbenja D, Zakari U (2013). Comparative evaluation of the nutritional and sensory quality of different brands of orange-juice in Nigerian market. African J. Food Science, 7(12), 479-484.

Ogbonna AC, Abuajah Cl, Ekpe GE (2013). A comparative study of the nutritive factors and sensory acceptance of juices from selected Nigerian fruits. Croatian J. Food Technology, Biotechnology and Nutrition, 8(1-2), 47-51.

Oguntola ED, Akinyele O (1995). Nutrient Composition on the Commonly Eaten Foods in Nigeria. In: Raw Processed and Prepared Food Basket. Foundation International Publishing, Ibadan. USDA (2014). Nutrition Facts for Carrots, Raw [Includes USDA 
Okwori et al. 039

Commodity Food A099], per 100g, USDA Nutrient Data Base for Standard (10/ 8/ 2016) Reference, Version SR-21.

Vasavada PC (2003). Microbiology of Fruit Juice and Beverage. In: Foster T and Vasada P.C (eds). Beverage Quality and Safety, pp. 95-123.
Wall MM (2006). Ascorbic acid, vitamin C and mineral composition of banana (Musa spp.) and papaya (Carica papaya) cultivars grown in Hawaii. J. Food Composition and Analysis, 19(5), 234-445 